\title{
DEVELOPING SOUTH EAST EUROPEAN COOPERATIVE CRISIS MANAGEMENT CAPACITY $^{1}$
}

\author{
Todor TAGAREV
}

\section{Background}

For a century the Balkans were seen as the powder keg of Europe. Transformations after the end of the Cold War once again triggered violence. Throughout the 1990s, the region drew in considerable crisis management resources benefiting from the efforts of the international community. Practically, the potential for regional security response has not been utilized.

Now, with the launch of the Multinational Peace Force South-East Europe (SEE), the Stability Pact and the encouraging developments in the Federal Republic of Yugoslavia, for the first time in history all SEE countries demonstrated their willingness to cooperate in conflict prevention and crisis management and to take responsibility for security and stability in their own home. However, given cultural diversity, resource constraints, and lack of market experience in some of the countries, the challenge is in their ability to do so.

SEE countries proved their willingness to cooperate through promotion of a number of political and diplomatic initiatives in various frameworks. The success of the SEE Defence Ministerial (SEDM) process is just one example. ${ }^{2}$ The military cooperation quickly expanded to encompass various security and crisis management initiatives. ${ }^{3}$ One remarkable achievement is the common assessment of regional security challenges and opportunities in the SEECAP paper ${ }^{4}$ setting the stage for comprehensive security cooperation.

However, the cooperative implementation of means for crisis management is often hindered by lack of adequate organisation and appropriate technology, as well as other interoperability challenges. For example, the delay in announcing the operational readiness of the SEE Brigade (SEEBRIG ${ }^{5}$ ) is caused mostly by lack of 
common field communications and information system. In other words, a solid political and military effort hangs on a technology need to provide interoperability among national forces contributed to SEEBRIG. That means a lack (or very limited efficiency) of capability to employ operationally an otherwise excellent tool.

\section{Proposal}

Currently, given political will and common understanding, the challenge is to build and sustain cooperative capabilities to deal with crises of various nature while efficiently using limited financial and other resources. Most of the capabilities may be nationally owned, but will be prepared and available to deal with crisis in the whole region of South East Europe.

The proposal herein is to launch a SEE Cooperative Crisis Management Initiative that would implement a regional Strategy for Development of SEE Cooperative Crisis Management Capacity. This strategy shall be "regionally-owned." Once agreed by the SEE states, it may serve as indication for priorities in utilising national and international funding, i.e., funding through the Stability Pact for South East Europe.

This SEE initiative will contribute to the European Union capabilities to perform the "Petersberg Tasks." Adding to the military cooperation among SEE countries, it will allow to develop and sustain, in a coordinated manner, ${ }^{7}$ regional cooperative capabilities to meet risks and challenges of ${ }^{8}$ :

- Natural disasters including earthquakes, floods, avalanches, volcanic eruptions, massive forest fires and landslides, severe storms and draught, and extreme temperatures;

- Technological disasters, industrial accidents and pollution, i.e., nuclear reactor incident, hazardous material spill, etc.;

- Air crashes, railway accidents and ship wrecks;

- Pandemics;

- Pest infestations;

- Massive refugee flows, particularly as a consequence of armed conflicts and violence;

- Insufficient early warning.

The initiative shall support, to the extent practical, SEE cooperation aimed at preventing risks and dealing with cases of :

- Organised crime, in particular money laundering, illegal trafficking of arms, narcotics, human beings, components and materials for weapons of mass destruction. Links with corruption and finance for terrorist and illegal armed groups activities; 
- Destabilising accumulation and illegal transfer of conventional weapons including small arms and light weapons and ammunition;

- Non-observance or circumvention of arms control, disarmament and nonproliferation obligations;

- Illegal migration, especially if connected with organized crime;

- Corruption.

\section{Logic of the proposal}

The cooperative approach to crisis management would allow to lower risks to security and stability in South East Europe and to promote common political standards, or "code of conduct," i.e., in devising and implementing strategy and doctrine in an open transparent manner. Broader cooperation in crisis management will contribute to building confidence and trust among governments and people in SEE. It will facilitate rapid dissemination of best practice and the realisation of economy of scale both through intergovernmental cooperation and cooperation in utilising military and civilian crisis management resources.

\section{The way foreword}

\section{Definitions of Cooperative Crisis Management Capability/ Capacity}

For the purposes of this paper Cooperative Crisis Management Capability (CCMC) may be defined as

availability of national and/or multinational assets (organised people /formations/, equipment and infrastructure, including crisis and emergency management /command and control/ infrastructure)

with the ability (arrangements are in-place; plans are available, procedures are known; people/formations are trained) to prevent, counter and manage the consequences of a crisis.

CCM Capability is relative. It is assessed against a crisis scenario with a given scope and intensity.

The regional Cooperative Crisis Management Capacity may be defined as

capacity to apply regional CCM capabilities to prevent, counter and manage the consequences in a set of concurrent, overlapping or sequential crises of various nature.

In a broader understanding a "regional" $\mathrm{CCM}$ capacity would account for arrangements and assets to call for and utilise out-of-region support. ${ }^{9}$ 


\section{Existing regional initiatives related to crisis management}

The development of cooperative crisis management capacity will build substantially on the existing military cooperation and the cooperation in emergency management. The regional military cooperation is established largely in the framework of the South Eastern Defence Ministerial (SEDM) through the Multinational Peace Force South East Europe (MPFSEE). MPFSEE currently includes one mechanised brigadeSEEBRIG-with units from seven countries and a battalion-sized Engineering Task Force.

The cooperation in emergency management evolves within two main initiatives. The Disaster Preparedness and Prevention Initiative (DPPI) in the Stability Pact already produced a framework document, known as "Gorizia Document"10 that served to provide strategy outline for common action in seven areas: Information sharing and networking; Standardisation and harmonisation, Preparedness and planning exercises, Cooperative development, conduct and evaluation of disaster management training events; Public awareness and media relations; Strengthening local structures; and Border crossing procedures. Furthermore, the initiative already resulted in a joint military-civil fire fighting exercise "Taming the Dragon - Dalmatia 2002" in Croatia, 22-24 May 2002. ${ }^{11}$

The second major initiative led to the establishment of a Civil-Military Emergency Planning (CMEP) Council for South East Europe. ${ }^{12}$ The Council is intended to coordinate efforts in all phases of the disaster management cycle: mitigation, prevention, planning, response and reconstruction. The areas of cooperation include: development of processes and means for practical regional cooperation in disaster management; development of improved coordination methods for all phases of the disaster management cycle; development of regional risk assessment; development of recommended response plans for the greatest risks; development of standard operating procedures and promotion of interoperability; planning, organisation and conduct of exercises and training. In December 2002, CMEP conducted the first large scale exercise using distributed simulation technologies. Greece and the United States were co-hosts of the exercise, based on a scenario involving large earthquake.

Another related project is a follow-up of SEECAP aiming at exchange of political, military and other early warning, conflict prevention, and crisis management information. Known by the abbreviation SEECHANGE, the project has already progressed with the adoption of a Concept Paper. ${ }^{13}$ This project is implemented in the framework of the NATO affiliated South East Europe Security Cooperation Steering Group (SEEGROUP).

In South East Europe, there is a recognised need for close civil-military cooperation in crisis management. The implementation of this understanding is facilitated 
technologically through the US-sponsored project to establish 'National Military Command Centres' (NMCC) in several countries in South East Europe. The NMCC Concept of Operations accounts for the need to assure effective cooperation between civilians and the military in managing variety of crisis and emergency situations. ${ }^{14}$

In a broader understanding of crisis management, the development of CCM capacity shall account for initiatives aimed at countering arms proliferation, anti-corruption initiatives and initiatives that involve cooperative approach to law enforcement.

Certainly, a strategy for development of SEE cooperative crisis management capacity shall account for related sub-regional initiatives or initiatives in overlapping regions, i.e., BlackSeaFor. ${ }^{15}$

Compared to existing initiatives, this proposal adds in scope and level of coordination and cooperation among SEE countries. First, it covers emergency management, disaster preparedness and prevention, expanding the scope to bridge 'civilian emergency management' to the Petersberg tasks and to link more closely civilian structures and the military. It also has the potential to coordinate emergency management to particular aspects of law enforcement. Secondly, while existing initiatives aim to improve planning and preparedness to use existing national resources, we envision coordinated, and later - joint, development of crisis management capabilities. That shall include coordinated organisational development, joint procurement of the necessary technology and coordinated or joint development of the supporting information infrastructure. Ultimately, it may lead to joint (regional) ownership of crisis management infrastructure and other assets.

\section{Approach}

The implementation of the proposal requires clear understanding of objectives and cohesive regional strategy. Efforts need to be well coordinated, avoiding duplication of efforts and guaranteeing increasing levels of interoperability.

Major components of the approach will aim to achieve:

- Compatibility of conceptualisation and normative regulation of "crisis management."

For example Bulgaria, with participation of non-governmental organisations, is currently debating a new Concept and a Law for Crisis Management. Experience shows that even in a single country it is not easy to delineate and define in strict legislative terms 'hard' and 'soft' security threats and, respectively, responsibilities of various ministries and state agencies. 
This component is essential to provide commonality of terminology and procedures, standardisation of reporting methods, and overall interoperability of crisis management assets.

- Agreement on procedures for crisis management.

Existing agreements on using the Multinational Peace Force in South East Europe, as well as the progress within DPPI and the CMEP initiative provide a sound basis for elaboration of more general procedures for crisis management.

- Joint or, at least, coordinated procurement.

Equipment, systems for command and control, infrastructure, etc., shall be developed jointly in well-coordinated manner to provide for: (1) interoperability or, ideally, commonality of equipment, and (2) efficient use of resources both for acquisition (up-front costs) and for life-cycle support.

As a side effect, joint procurement initiatives may facilitate economic cooperation in SEE.

- Organisational arrangements

Essential is the establishment of a permanent regional organisationRegional Crisis Management Centre - tasked to coordinate development and implementation of SEE cooperative crisis management capabilities. This Centre may be established on the premises of the SEEBRIG HQ in Plovdiv, Bulgaria, after the HQ transfers to Constanza, Romania, in the autumn of 2003.

The Regional Crisis Management Centre shall have a permanently assigned staff representing the participating countries. The Centre will serve as a focal point for work coordination. It will provide readily available support to decision makers during crises. The staff will monitor developments in SEE and issue crisis early warning. The Centre will serve as repository for crisis management plans and other information related to status of assets, capability development plans (programmes) and projects, development and support for implementation of crisis management training and exercises, etc. From a technical point of view, one obvious role for the Centre is to serve as developer and holder of the Joint Technical Architecture ${ }^{16}$ for the SEE Cooperative Crisis Management Initiative.

\section{Mechanics}

The implementation of this proposal would require performing the following steps: 
- Agree, broadly, on the scope of a potential SEE Cooperative Crisis Management Initiative;

- Agree on the terminology used;

- Create a data bank of existing national and regional crisis management capabilities;

- Create a data bank of regional and major national initiatives, as well as initiatives for overlapping regions, for development of crisis management capabilities;

- Model regional crisis management in order to:

- Identify gaps in existing and planned crisis management capabilities in SEE;

- Compare organisational designs and 'command' arrangements;

- Assess acquisition proposals and initiatives;

- Devise and discuss, prior to the launch of the initiative, a Strategy for Development of SEE Cooperative Crisis Management Capacity.

All these steps might be combined in one feasibility study. A parallel activity would be needed in order to raise awareness of policymakers and practitioners of the utility of the proposed initiative and the required comprehensiveness of the approach, to cover normative regulation, procedures, organisation, training and technology insertion.

The implementation of the Strategy would imply advancement of a common, or at least coordinated policy for consistent organizational development and technology acquisition. This will include policies for coordinated, and in the future - joint procurement of technologies and systems for information collection, situational awareness, distributed decision making, communications, command and control in managing multinational multi-agency crisis prevention and response to crises of armed nature, natural disasters, industrial accidents, and humanitarian crises.

It shall account for potential organisational and technology solutions to law enforcement tasks, such as prevention of and counteraction to arms proliferation; illegal trafficking of people, drugs and goods; money laundering, and terrorism.

Of particular interest will be the areas requiring advanced technology implementation in close civil-military cooperation, such as emergency management, control of maritime and river traffic, and coastal zone management. Furthermore, advanced IT, when implemented in a regionally coordinated manner, has the potential to contribute to organizational development plans (development of multinational crisis management formations, civil and civil-military emergency resource planning, 
disaster preparedness, networked capabilities to fight organized crime, etc.; cooperative command arrangements for conflict prevention and crisis response; common early warning, situational awareness, consultations and distributed decisionmaking, and management of multi-national multi-agency crisis response.

Thus, technology insertion and development of infrastructure will be an important component of the strategy. However, knowing that technology that is not integrated into crisis management and response systems will not be effectively used during the response, ${ }^{17}$ the most important practical result will be the increase of coherency of organisational and technological developments of cooperative crisis prevention and crisis management capabilities.

\section{Potential Support and Beneficiaries}

Several on-going initiatives may contribute substantially to the one proposed herein. Main among them are the EU-sponsored Stability Pact for South Eastern Europe, in particular its Working Table $3{ }^{18}$ and the NATO's South East Europe Initiative and the related South East Europe Security Cooperation Steering Group (SEEGROUP). ${ }^{19}$

The countries in South East Europe are the obvious beneficiaries from the implementation of this proposal. International organisations and donor countries, however, will also benefit from it, since it will allow for more efficient spending of limited resources while building regional capacity to deal with the problems of SEE. No less important is that the region itself will define priority needs for cooperative crisis management capabilities. Sound foundation for that is the common regional assessment of security threats and challenges in the SEECAP paper and the process for updating it.

\section{Conclusion}

Cooperative approaches to security in South East Europe are strongly encouraged by international organisations. The need for cooperation is also well understood by a number of governments and non-governmental think tanks.

Certain preconditions for such cooperation are already in place. Psychologically, the formation of a common brigade consisting of military units of most nations in SEE, as well as the common assessment of the security challenges, already made a breakthrough. Politically, there is a will to cooperate not only in crisis management, but also in broader security initiatives. Financially, regional resources are limited; however, adding outside assistance, they would allow sizable cooperative development of crisis management capacity.

The main obstacle is in the lack of in-region organisational capacity to deal with a problem of such complexity. Furthermore, there is no common understanding of 
'crisis management,' and the procedures for procurement differ widely among SEE countries. We assume, that there is no instance when countries in the region themselves have managed common funds to acquire equipment under market conditions.

Fortunately, none of these obstacles is insurmountable. Following clear objectives, the implementation of the proposal herein will provide the necessary organisational capacity to guarantee efficient use of resources in SEE, including outside assistance. Thus, it will also increase the credibility of regional initiatives to provide for secure and prosperous future of South East Europe - part of the unified European continent.

\section{Notes:}

1 The first version of this paper was presented in May 2002 at the ESCADA meeting in Sofia. The paper was improved benefiting from the Sofia discussion. Improved version was discussed during the ESCADA meeting in Portoroz, Slovenia, in October 2002. For details on the ESCADA (Extending Security Co-operation and Defence Arrangements) project and recommendations the reader may refer to Security and Defence in SouthEastern Europe, Harmonie Papers 16 (Groningen, The Netherlands: Centre for European Secxurity Studies, March 2003).

For more information see Ognyan Minchev, Valeri Ratchev and Marin Lessenski, eds., Bulgaria for NATO 2002 (Sofia: Institute for International and Regional Studies, 2002); Todor Tagarev, "Bulgarian Armed Forces and National Security Policy: Shaping the Security Environment in South East Europe," in Almost NATO: Partners and Players in Central and Eastern European Security, ed. Charles Krupnick (Lanham, Md.: Rowman \& Littlefield, 2003), pp. 119-155. We are not aware of the existence of Web site regularly informing on SEDM activities. Initiatives during the Romanian Chairmanship of the CEDM Political-Military Steering Committee are presented at http://www.mapn.ro/english/news/newsletters/eng4.htm. 
3 See the article by Petya Dimitrova in the current volume.

4 South East Europe Common Assessment Paper on Regional Security Challenges and Opportunities (SEECAP), adopted May 2001, Budapest, Hungary. <http://www.nato.int/ docu/comm/2001/0105-bdp/d010530b.htm> (5 Nov 2001).

5 SEEBRIG (The South East European Brigade) is the main military formation of the Multinational Peace Force South East Europe. The Headquarter of this combined arms brigade is currently stationed in Plovdiv, Bulgaria, and is scheduled to move to Romania in the fall of 2003.

6 Humanitarian and rescue operations, peace-keeping and crisis management, defined in the Petersberg Declaration of 19 June 1992 as a pivotal element in developing the Western European Union (WEU) as the defence arm of the EU. The Treaty of Amsterdam has specifically incorporated these "Petersberg tasks" in the new Article 17 of the EU Treaty. See Petersberg Declaration (Petersberg tasks), <http://europa.eu.int/ scadplus/leg/en/cig/g4000p.htm> (12 June 2002).

According to General (Ret.) Carlo Jean, "Greater coordination of the effort of the international community is absolutely necessary." Presentation at the ESCADA Planning Meeting (Groningen, The Netherlands, 19 April 2002).

8 List adapted from SEECAP, the Agreement on the Establishment of the Civil-Military Emergency Planning Council for Southeastern Europe and the Concept of Operations for the National Military Command Centres (NMCC) project. No attempt to prioritise was made.

Analogous to the NATO concept of Host-Nation Support (HNS) capabilities.

The Gorizia Document, Regional Report of the DPPI Operational Team (Special Coordinator of the Stability Pact for South Eastern Europe, Disaster Preparedness and Prevention Initiative (DPPI), May 2001).

"Joint Efforts in Disaster Relief," Newsletter, Special Co-ordinator of the Stability Pact for South Eastern Europe, Issue 14 (28 June 2002): 8.

For the evolution of the CMEP initiative the reader may refer to A. Martin Lidy, M. Michele Cecil, Edwin J. Pechous, and Edward F. Smith, Civil-Military Emergency Planning Council, Bucharest Conference Proceedings (Arlington, VA: Institute for Defense Analysis, 28 July 2000). The Agreement on the Establishment of the CivilMilitary Emergency Planning Council for Southeastern Europe was signed in Sofia on 3 April 2001.

Chair's Progress Report of the Work in the First Half of 2002 - South East Europe Security Cooperation Steering Group (SEEGROUP), <http://www.nato.int/pfp/romania/ seegrouplhalf.htm> (21 August 2002).

For details the reader may refer also to Nikolay Petrov, "National Military Command Center - From Idea to Implementation," Information \& Security: An International Journal 6 (2001): 69-81. <http://www.isn.ethz.ch/onlinepubli/publihouse/infosecurity/ volume_6/a2/a2_index.htm> (12 April 2002).

15 Refer to the article by the Chief of Staff of the Bulgarian Navy Peter Petrov, "Towards Creation of a Unified Information System of the Navies of the Black Sea Countries," Information \& Security: An International Journal 6 (2001): 69-81. <http://www.isn. ethz.ch/onlinepubli/publihouse/infosecurity/volume_6/a4/a4_index.htm $>\quad(12$ April 2002). 
16 See for example C4ISR Architecture Framework, Version 2.0 (Washington, DC: C4ISR Architecture Working Group, December 1997).

17 John R. Harrald, Future of Emergency Management in the US following Sept. 11 Terror Attacks (Institute for Crisis, Disaster, and Risk Management, The George Washington University, October 2001), <http://www.seas.gwu.edu/ icdm/Oct1.htm> (12 Nov 2001).

18 Other Stability activities, such as the Anti Corruption Initiative may support this proposal in specific areas. Other activities within Working Table 2 will be of interest, i.e., infrastructure development, e-SEEurope, etc.

19 For details refer to James Appathurai, "NATO's evolving partnerships: Promoting regional security," NATO Review 49, no. 3 (Autumn 2001): 13-15.

TODOR TAGAREV is Director Programmes of the Centre for National Security and Defence Research at the Bulgarian Academy of Sciences. He was the first Director of the Defence Planning Directorate of the Bulgarian Ministry of Defence since its establishment in early 1999. Since May 2001 until late 2001, he served as Director for Armaments Policy and National Armaments Director. He graduated from the Bulgarian Air Force Academy in 1982 with M.Sc. degree in electrical engineering and received a $\mathrm{PhD}$ degree in systems and control from Zhukovsky Air Force Engineering Academy, Moscow, in 1989. Dr. Tagarev is a 1994 Distinguished Graduate of the US Air Command and Staff College at Maxwell Air Force Base, Ala., and a 1994 Distinguished Young AFCEAn. He is Editor of Information \& Security: An International Journal <http://infosec.hit.bg>. Dr. Tagarev specialises in the integration of information technology with security and defence policy, system analysis, computer modelling and prediction of complex processes.E-mail: tagarev@space.bas.bg. 